\title{
1961: O Assalto do Santa Maria e o Desmoronar do Regime Salazarista em Portugal
}

Heloisa Paulo*

heloisapaulo25@gmail.com

Resumo: Em Janeiro de 1961, um episódio marca a história da oposição ao salazarismo em Portugal: o sequestro do paquete Santa Maria, uma embarcação de luxo e um dos orgulhos do regime de Salazar. A bibliografia em torno do episódio do Santa Maria alcança um número razoável de títulos, quer em português, quer em espanhol, galego ou catalão. No entanto, a grande maioria é composta por relatos de participantes. O nosso objectivo é a análise dos relatos existentes, trazendo um novo ângulo de interpretação para o facto.

Palavras-Chave: Oposição, Salazar, Memória, Relações Brasil-Portugal.

As Ditaduras Ibéricas e os Seus Movimentos de Contestação: Resistência e Combate

Todas as Nações livres devem aos povos ibéricos, por fraternidade humana e defesa da liberdade, apoio ao combate que estão travando contra a tirania que as oprime (CORTESÃO, 1947, p. 1).

Quando, em 1931, é instaurada a República em Espanha, um grupo de exilados espanhóis deixa Paris, levando consigo o compromisso de, uma vez no poder, dar apoio aos exilados portugueses da ditadura militar instaurada em Portugal a partir de 28 de Maio de 1926. Na verdade, a cumplicidade estabelecida nos anos de exílio ganha força no período republicano espanhol e nas décadas de combate aos regimes ditatoriais ibéricos nas décadas que se seguiram à vitória de Franco.

* Investigadora do Centro de Estudos Interdisciplinares do Século XX (Ceis20), Universidade de Coimbra. 
A partir de 1927, com uma grande revolta no Porto, e nos anos que se seguem, os republicanos portugueses continuam a luta contra $o$ regime imposto em Portugal, capitaneando alguns dos movimentos de contestação armada que visam o retorno à normalidade democrática no País ${ }^{1}$. Nesta luta de 48 anos, portugueses e espanhóis cruzam, por diversas ocasiões, um caminho comum como durante a Guerra Civil Espanhola, quando planeiam em cooperação a luta contra Franco e a deposição de Salazar.

Entre 1936 e 1939, inúmeros republicanos portugueses combatem integrados nos batalhões militares da República, enquanto nomes sonantes da oposição exilada, Jaime de Morais, Jaime Cortesão e Alberto Moura Pinto planeiam uma concentração de tropas na região da Catalunha, com o objectivo de invadir Portugal e fomentar a revolta contra o regime de Lisboa. $\mathrm{O}$ avanço das tropas franquistas e a descoordenação dos envolvidos na conspiração em Portugal, levam ao fracasso daquele que ficou conhecido como o "Plano Lusitânia". Assim sendo, em Fevereiro de 1939, quando milhares de espanhóis cruzam a fronteira em direcção ao território francês, os portugueses seguem-lhes as pegadas, acompanhando o exílio de um sonho ibérico, uma Península republicana e igualitária² ${ }^{2}$.

Nos anos seguintes, numerosas acções unem outra vez os opositores dos regimes ditatoriais português e espanhol. Na década de 1940, é estabelecida uma "aliança" formada pelos opositores portugueses exilados no Brasil, capitaneados por Jaime de Morais, Jaime Cortesão e Alberto Moura Pinto, e representantes do governo republicano espanhol no exílio, nomeadamente o grupo ligado ao movimento da Galeuzca ${ }^{3}$. Na frente deste grupo, um velho amigo dos portugueses, o poeta Afonso Castelao ${ }^{4}$ que, após uma passagem pelo Brasil, parte para o México com uma credencial portuguesa para representar os interesses dos mesmos frente ao governo republicano espanhol no exílio. O objectivo é obter o reconhecimento dos dois grupos de exilados, o português e o espanhol, como representantes legais dos governos dos seus países na recém-criada ONU. No entanto, as Nações Unidas não aceitam qualquer representatividade de ambos os sectores exilados 5 .

Mas, a actuação comum de propaganda contra os regimes ditatoriais ibéricos perdura nos anos seguintes. Em 1947, é criado o jornal Libertação, editado no Brasil, com o apoio da Associação Brasileira dos Amigos do Povo Espanhol e a Sociedade dos Amigos da Democracia Portuguesa, que, igualmente, visa o combate em prol da restauração da democracia em Espanha, e em Portugal (PAULO, 2009). 
Nos anos seguintes, outras acções são realizadas, organizadas por outros sectores oposicionistas ibéricos, nomeadamente pelos Partidos Comunistas Espanhol e Português. No entanto, no final da década de cinquenta, o aparecimento do Directório Revolucionário Ibérico de Libertação, o DRIL, e a posterior tomada do paquete português Santa Maria, são os marcos mais significativos da actuação conjunta das duas oposições desde o final da Guerra Civil espanhola ${ }^{6}$.

\section{A Oposição Portuguesa no Brasil e a formação do DRIL}

O Brasil sempre foi o destino preferencial da emigração portuguesa e o refúgio de muitos dissidentes dos diversos governos de Portugal: no período do conservadorismo de D. Miguel, acolhe os liberais; quando da República, serve de local de exílio para os emigrados políticos monárquicos. A partir do advento da ditadura em Portugal, o território brasileiro passa a receber os opositores ao regime, que são acolhidos pelos seus compatriotas e companheiros de ideais políticos, mas são olhados com desconfiança pelos membros conservadores da colónia.

Com o aproximar do fim do Estado Novo de Vargas, os exilados portugueses aproveitam o clima de liberdade para promoverem manifestações públicas, solicitando o fim do salazarismo em Portugal. Em Abril de 1945, temos a criação do Comité Português Anti-Fascista, do qual participam inúmeros nomes de oposicionistas, englobando elementos de diferentes matizes políticas, desde comunistas até republicanos, no qual incluímos republicanos, como Sarmento Pimentel, monárquicos, como o escritor Tomás Ribeiro Colaço, anarquistas, como Roberto das Neves, ou comunistas, como Joaquim Novais Teixeira e e o matemático Aniceto Monteiro. Com a legalização do Partido Comunista Brasileiro, entre 1945 e 1947, a aproximação entre comunistas brasileiros e portugueses favorece o patrocínio de iniciativas singulares, gerando momento de confraternização entre os defensores do comunismo em ambos os países, como na inauguração da "Exposição da Imprensa Clandestina Portuguesa", realizada na Associação Brasileira de Imprensa, em 25 de Janeiro de 1947, com a presença do próprio Prestes, como convidado especial (PAULO, 2009).

Na década seguinte, as manifestações dos exilados continuam. Durante a visita do Presidente português Craveiro Lopes ao Brasil, os opositores, contando com o apoio de jornalistas e escritores, como Rubem Braga, aproveitam para denunciar publicamente o regime de Salazar ${ }^{7}$. Para além das publicações, são feitas prisões de elementos vinculados ao Partido Comunista Português, 
que tentavam distribuir panfletos contra o salazarismo durante a estada de Craveiro Lopes no Rio de Janeiro ${ }^{8}$.

Mas o facto mais marcante do período é a chegada ao Brasil do ex-candidato das eleições portuguesas de 1958, o General Humberto Delgado, que, após um período de permanência nas dependências da embaixada daquele país em Lisboa, obtém a concessão do exílio territorial em terras brasileiras, sendo recebido por opositores e simpatizantes, reunidos em torno de uma associação com o seu nome. Em breve, as contraditórias atitudes do antigo general levam ao seu rompimento com uma boa parte dos exilados portugueses. Mas, antes disto, um acontecimento marca a trajectória da oposição portuguesa no exterior e o seu combate contra o salazarismo. Entre 22 de Janeiro e 4 de Fevereiro de 1961, um grupo de portugueses e espanhóis sequestra o paquete português Santa Maria, realizando o primeiro acto do terrorismo moderno contra regimes ditatoriais 9 .

A acção é empreendida em nome do DRIL, Directório Revolucionário Ibérico de Libertação ${ }^{10}$, criado por exilados espanhóis e portugueses em território venezuelano, reunindo nomes como Xosé Velo Mosquera, antigo participante da "Mocedade" do Partido Galeguista e membro da guerrilha antifranquista ${ }^{11}$, José Fernández Vázquez (Jorge de Sotomayor), membro da Marinha republicana na Guerra Civil, do lado espanhol, e Humberto Delgado e Henrique Galvão, pelo lado português, ambos ex-membros do regime de Salazar ${ }^{12}$.

Tendo realizado inúmeros actos em território espanhol, o DRIL, agora com o auxílio português, tenta uma acção de repercussão internacional, ou seja, o aprisionamento de um navio. O simbolismo do acto reside no facto de que, uma vez em águas internacionais, toda a embarcação é aceite juridicamente como "parcela territorial" do seu país de origem ${ }^{13}$. Assim sendo, o seu aprisionamento pode ser considerado como um verdadeiro "assalto" ao Estado do qual é representante. A tomada pelo DRIL de um navio português ou espanhol significaria a "deposição" de uma das duas ditaduras, um acto político de revindicação do reconhecimento internacional para a luta pela democracia levada a cabo pelos opositores exilados.

Assim sendo, o Santa Maria é capturado pelo grupo no Curaçao e após alguns dias de trajectória no mar, acaba por atracar no porto do Recife, graças ao apoio dado por Jânio Quadros ao movimento, através dos contactos mantidos com Henrique Galvão ${ }^{14}$. No entanto, o episódio gera um verdadeiro fenómeno mediático contrário aos regimes ibéricos e dá origem a visões bastantes diferenciadas do ocorrido. 
O ASSALTO AO SANTA MARIA: VÁRIOS RELATOS E UMA LEITURA

Porquê este atraso? Porque os nossos comandantes, chegados ao ponto de concentração puseram-se a contar as estrelas, cada um para seu lado, sem que ninguém ousasse dar a ordem de ataque... foi necessário que dos subordinados saísse uma iniciativa, ou vinha a ordem ou dispersávamos... (- não sei para onde?) para que o nó se desatasse e enfim partíssemos para a acção. Como o grupo comandado pelo Sotomayor com a quase totalidade dos espanhóis, tinha por objectivo o assalto à ponte de comando, e o Grupo comandado pelo Galvão com dois ou três espanhóis à mistura, estava encarregue de iniciar as hostilidades tomando conta da sala da rádio e de seguida a casa das máquinas e camarotes dos oficiais, estes situados por baixo da ponte de comando, o problema resolveu-se naturalmente. O Sotomayor atacou como ele quis, e o Galvão dirigiu os "seus homens"como lhe pareceu (MORTÁGUA, 2009, p. 225).

Com fardas de caqui, sem quaisquer insígnias, encontrámo-nos no ponto determinado. Esperámos aí alguns minutos, conversando em pequenos grupos, alguns sentados à beira da piscina, outros debruçados na amurada, com o fim de afastar o nervosismo emocional que é parte dos momentos dramáticos da vida das pessoas. [...].

À 1,45 dei ordem de ataque. Estávamos divididos em dois grupos de assalto. Um, comandado por Sotomayor, ocuparia a sala de rádio, a ponte e a casa do leme. O outro, sob meu comando, atacaria o ponto do segundo convés onde o capitão, o imediato e outros oficiais do navio tinham as suas cabines (GALVÃO, 1973, p. 173).

A bibliografia em torno do episódio do Santa Maria já alcança um número razoável de títulos, quer em português, quer em espanhol, galego ou catalão ${ }^{15}$. Quanto aos relatos na primeira pessoa temos já alguns como o do próprio Henrique Galvão, um antigo oficial salazarista que rompe com o regime no final da década de quarenta, de Jorge Soutomayor, um ex-combatente da Guerra Civil espanhola, de Miguel Urbano Rodrigues, jornalista e opositor ao regime de Salazar, e de Camilo Mortágua, emigrante na Venezuela que, após o contacto com Galvão, passa a militar na luta armada contra o regime salazarista, para além de entrevistas e depoimentos de muitos dos envolvidos. O nosso objectivo não é propriamente averiguar a "verdadeira" sequência dos factos, ainda que no decorrer da narrativa as contradições das versões surjam, invalidando algumas destas. Antes de mais, o que se pretende é explicitar o "porquê político" dos relatos e da tentativa 
de protagonismo por parte dos seus autores, sendo que, ao mesmo tempo, traçamos uma linha dos acontecimentos.

Na noite de 21 para 22 de Janeiro de 1961, um grupo armado toma conta de um dos paquetes de luxo da marinha mercante portuguesa, 0 Santa Maria. O golpe fora planeado em detalhe pelos membros do DRIL, e a escolha do "alvo" gera a primeira polémica nas narrativas do episódio, já que uma decisão apontava a nacionalidade do navio a ser capturado como fundamental para a designação do chefe político da operação. Neste sentido, tomando em consideração que o sector espanhol dispunha de um homem da marinha com experiência e que, desta forma, assumiria o comando do navio, restava aos portugueses o comando político. A escolha do Santa Maria como o "melhor candidato" (GALVÃO, 1973, p. 151) para a chamada "Operação Dulcineia"16 é contestada pelo comando espanhol que acusa o militar português da alteração de um "relatório" a respeito das condições de segurança e controlo das rotas de navegação de um outro navio de nacionalidade espanhola ${ }^{17}$. As afirmações neste sentido são repetidas em todos os relatos encontrados:

En el decurs d'aquest primer dia, els assaltants prenen possessió del vaixell i poden verificar amb indignació que algunes des les informacions aportades per Galvão i els sus homes en l’etapa de planificació són errònies: de les llanxes salvavides, tan sols una té un motor adequat, i l'armament que troben són fussells de tira l plat (VELO apud MONTANYÀ, 2004, p. 118).

Intencional ou não a escolha do Santa Maria é de mais-valia para o grupo português, já que o coloca no "comando político" da operação. Segundo Velo (apud MONTANYÀ, 2004, p. 105), no entanto, o paquete português é a escolha mais correcta para o projecto:

Segons Velo, primer s'havia pensat en un vaixell espanyol, i si es va escollir el transatlàntic portugués Santa Maria va ser perquè de tots els que passaven pel port de La Guaira a Caracas (Veneçuela), era el més important, el més modern, la qual cosa facilitaria la repercurssió publicitària de l'acció arreu del món.

Uma vez escolhido o "alvo", a narrativa dos movimentos posteriores não é só um exercício de memória daqueles que oferecem o seu testemunho, mas um discurso de justificativas políticas que tendem a dar o protagonismo principal a cada um dos sectores políticos envolvidos, quer sejam os repre- 
sentantes espanhóis, ou ainda, elementos que no interior do DRIL passam a representar outras forças no decorrer da sua trajectória política. Desta forma, são evidentes as diferenças entre as narrativas de Galvão e dos demais citados, já que a do comando português é publicada "no calor da hora", ou seja, passado pouco tempo do ocorrido e quando as alianças políticas ainda mantém um ténue laço. Neste período, 1961, as cisões internas estão apenas esboçadas, mesmo a mais "marcante", aquela que põe em campos opostos Henrique Galvão e Humberto Delgado ${ }^{18}$. Os demais relatos, escritos bem mais tarde, traduzem posicionamentos assumidos posteriormente, em especial o rompimento do DRIL com Galvão e com boa parte da oposição portuguesa.

Um exemplo bem elucidativo deste tipo de "mudança" é dado quando comparamos a forma pela qual os principais envolvidos, no caso dos narradores, tratam dos seus companheiros de jornada. Enquanto no relato de Galvão a figura de Sotomaior ganha relevo, enquanto militar, o que se compreende pelo papel de "líder político" que o narrador pretende desempenhar, na descrição do exilado espanhol, a imagem de Galvão sofre as críticas oriundas dos anos de afastamento e conflitos entre os dois sectores:

$\mathrm{O}$ rato em que fôramos obrigados a tornar-nos, começou a manobrar para escapar dos gatos. [...] O nosso perito naval, Sotomayor, sem nunca perder o seu bom humor e vivacidade, manobrou o rato tão habilidosamente que este escapou aos seus perseguidores, mesmo na área onde a busca lhes era mais fácil (GALVÃO, 1973, p. 195).

Separo-me de Velo e vou encontrar-me com Galvão. O Capitão recebe-me com um tal ar de General subestimado que, surpreendido, não sabia se me devia rir ou indignar. Embora o seu tom fosse excessivamente destemperado, armei-me de paciência e escutei-o.

- Porque é que o senhor mudou o plano táctico sem me consultar? Eu sou Capitão do Estado-Maior - como não podia gritar afogava-se em ira - e sei muito bem o que deve fazer-se. Não admito tais coisas de maneira nenhuma. Eu pensava comigo: 'Capitão do Estado-Maior, sem saber de outra guerra senão a que se faz à fauna africana ou às codornizes em Portugal [...] Que homem era este que nem sequer tinha em conta a minha condição de marinheiro de guerra e de Comandante da operação? (SOUTOMAIOR, 2010, p. 52-3).

Um outro memorialista, o jornalista Miguel Urbano Rodrigues, é citado por Sotomaior (2010, p. 217) como membro do DRIL, "o companheiro Urbano Rodrigues”, enquanto, já no presente século, a apreciação feita 
por este ao líder espanhol não o favorece enquanto membro do comando da operação:

[...] Sottomayor subia à ponte com frequência, fazia perguntas com ar conhecedor, mas havia algo na sua atitude que não me inspirava confiança. Nunca cheguei a uma conclusão sobre o nível real dos seus conhecimentos de navegação" (RODRIGUES, 2001, p. 213).

Os vínculos de Miguel Urbano ao PCP e o facto de Sotomaior escrever no momento do retorno da democracia à Espanha contribuem para uma imagem positiva do companheiro que, no entanto, não pretende deixar para o "companheiro" espanhol um maior protagonismo na narrativa, como veremos adiante. No entanto, os mesmos factores que levam Sotomaior a citar Miguel Urbano são decisivos para a descrição, ou melhor, a sua "omissão" nominal no relato de Galvão. Não tendo mencionado a sua presença no Santa Maria, ainda que narre a existência de um barco com jornalistas que chega até ao paquete em alto mar, Galvão refere-se a Miguel Urbano de forma indirecta através de um episódio posterior, quando o jornalista parte para Conacry, objectivando negociar com os movimentos independentistas: "Um oportunista da extrema esquerda, anti-portuguesa e anti-democrática, que passou recentemente algumas semanas em Conakry, regressou com a totalidade do problema africano no bolso [...]" (GALVÃO, 1973, p. 297).

Anticolonialista e anticomunista, Henrique Galvão logo rompe com Miguel Urbano "apagando-o" do seu relato. Por outro lado, o jornalista faz questão de afirmar a sua vinculação ao DRIL e o papel de destaque que lhe teria sido atribuído por Galvão na Operação Dulcineia. Na verdade, a aproximação entre os dois teria sido frutificado aquando, por um breve tempo, Miguel Urbano se afastou do PCP, rompendo com o jornal Portugal Democrático, seu representante no exílio brasileiro, e fundando um outro periódico, o Portugal Livre ${ }^{19}$ :

Galvão [...] apoiou o lançamento do jornal Portugal Livre. Não foi, entretanto, sem estranheza que um dia recebi dele uma estranha carta. Pedia-me que assinasse um documento que equivalia a uma carta-de-prego. Por ela me comprometia a participar em qualquer operação dirigida contra o fascismo português a ser levada adiante por uma organização revolucionária que estava a criar. O compromisso cheirava a pólvora. Mas não hesitei em assumi-lo (RODRIGUES, 2001, p. 199-200). 
Na continuação dos relatos, a busca pelo protagonismo de cada um dos narradores fica latente em alguns momentos, sobretudo naqueles de maior tensão e que implicam a tomada de decisões deveras significativas ao nível de comando ${ }^{20}$. Assim sendo a decisão do desembarque de um oficial ferido aquando da primeira investida à ponte da embarcação é fonte de mais uma polémica no relato ${ }^{21}$, já que o facto leva à localização posterior do navio, antes que este alcançasse segurança em alto mar. Galvão (1973, p. 184) assume a sua formação militar no relato do episódio e na decisão tomada, sempre afirmando o "consenso" de todos na solução encontrada:

[...] Uma consciência rigorosamente militar ou revolucionária, não teria hesitado: teria talvez, embora com muito pesar, deixado os dois homens morrer, de preferência a comprometer o êxito da ocupação e arriscar a segurança dos nossos homens. Uma consciência rigorosamente humanitária também não teria hesitado [...] Atormentados, oscilámos entre os dois pontos de vista [...] Chegámos afinal a uma conclusão: os dois homens seriam postos em terra.

Sotomaior, ao contrário de Galvão, não necessita demonstrar a coesão do DRIL, nem a persistência da acção conjunta com os portugueses. O seu relato é marcado por inúmeros "diálogos" que, segundo as suas afirmações, teriam sido trocados durante a ocupação do Santa Maria. Como em outros momentos da sua narrativa, mais uma vez, o episódio que cerca o desembarque dos feridos é transformado num palco de disputas entre os dois grupos e na afirmação da falta de visão política e da decorrente capacidade de comando de Galvão:

Discutimos o assunto. A minha resposta é no sentido de apoiar o desembarque dos feridos [...] A opinião mundial saberá apreciar a nossa atitude, porque humana. [...] Galvão enfurece-se, opõe-se; não se importa que dois homens morram e replica-me friamente:

- E se morrerem? Que morram, Soutomaior! Primeiro a nossa segurança! Não compreendo o seu sentimentalismo. Oponho-me terminantemente ao seu desembarque (SOUTOMAIOR, 2010, p. 134-5). ${ }^{22}$

No entanto, apesar das afirmativas de Sotomaior no seu relato, o testemunho de Víctor Velo afirma que este seguiria a linha de Galvão, ou seja, a opção de não desembarque dos feridos. Somente a intervenção de Pepe Velo os faria mudar de ideia (PIÑERO, 2008, p. 39; MONTANYA, 2004, p. 119). Sendo assim, a vivência militar de Galvão e o traquejo de Sotomaior na guerrilha cedem lugar 
aos argumentos diplomáticos de Velo, um "propagandista" da oposição galega. De resto, Camilo Mortágua é o primeiro a reconhecer a falta de maturidade do restante grupo português em acções do género, frente à larga bagagem trazida pelos espanhóis ${ }^{23}$. Este facto é constantemente "explorado" por Sotomaior no seu relato, realçando assim a importância da presença espanhola no interior do Santa Maria, malgrado a fama atingida por Galvão posteriormente como o condutor do assalto. É o que vemos quando Sotomaior passa a narrar o cerco e a perseguição que a esquadra norte-americana passa a fazer ao paquete, após a sua localização, ao expor os seus conhecimentos náuticos:

[...] Se o senhor fosse marinheiro em vez de Capitão de cavalaria saberia que, em caso de operações, os serviços de goniometria e rádio estão constantemente à escuta do inimigo. E neste caso não ponha em dúvida, nós, para eles, somos o inimigo (SOUTOMAIOR, 2010, p. 194).

A descrição dos contactos com a esquadra norte-americana oferece um painel dos possíveis "choques" de protagonismos no decorrer do episódio e que divide não só espanhóis e portugueses, mas sobretudo estes últimos. Antes de mais nada, cumpre salientar a importância do papel de "comando" nas conversações, visto os USA serem o representante ocidental bélico mais respeitável na dicotomia da Guerra Fria ${ }^{24}$. Enfrentar os seus representantes é chamar, para quem relata, o principal papel de interlocutor e, desta forma, $o$ elemento mais capaz de toda a operação tal como afirma Sotomaior:

Quando se aproxima a hora da conferência, Sotomayor chama-me a atenção para o torpedeiro americano, fazendo notar que os canhões estão descobertos e equipados com soldados como se fosse uma batalha. Protestamos e a exibição de poder termina imediatamente (GALVÃO, 1973, p. 237).

- Santa Liberdade a Gering: porque vêem os senhores em dispositivo de combate? [...]

- Nós não estamos em dispositivo de combate.

- Sou um ex-oficial da Armada Espanhola e sei muito bem o que digo. Se os senhores persistem nesta atitude temo que a entrevista não possa celebrar-se (SOUTOMAIOR, 2010, p.. 206).

O relato de Henri Zeiger (1961) vem confirmar as afirmações de Sotomaior ao colocá-lo como autor de uma frase onde afirma ser um "old sea dog" e a sua desconfiança quanto à postura assumida pela embarcação norte-ameri- 
cana. De igual forma e segundo o relatório do representante norte-americano, a conversação citada acima é feita em espanhol e português, o que poderia justificar o "assumido" protagonismo de um "recém chegado" ao paquete por ocasião do facto, Miguel Urbano Rodrigues, apesar da afirmação de Galvão (1973, p. 237) de que as ordens teriam partido dele próprio:

$\mathrm{Na}$ manhã seguinte, chegou a esquadra norte-americana, que incluía um submarino nuclear. Coube-me a tarefa de parlamentar com eles [...] As bocarras dos canhões estavam abertas, algumas voltadas para nós. A minha resposta foi 'Tapem os canhões. Antes disso não dialogamos (RODRIGUES, 2001, p. 215).

Apesar disto, o diálogo entre as autoridades navais norte-americanas e o comando do Santa Maria é qualificada de "d'amistosa" ${ }^{25}$, malgrado a atitude de "policiamento" assumida pela esquadra dos Estados Unidos.

Uma vez concluídas as negociações e confirmado o apoio do recém eleito presidente Jânio Quadros aos revoltosos, o paquete entra em águas territoriais brasileiras, agora rebaptizado de "Santa Liberdade". Neste interim, um outro episódio aparece nos relatos como mais um exemplo de narrativas diferenciadas: o "protesto" ou "motim" levado a cabo pelos passageiros durante a operação de desembarque. Conforme o posicionamento político do narrador, temos o uso das duas expressões acima e o acentuar ou atenuar do acontecimento no contexto total do episódio. Assim sendo, Henrique Galvão que descreve o facto muito próximo do ocorrido, minimiza o possível clima de revolta e descontentamento dos passageiro, oferecendo uma visão contrária aos relatos pró regimes ibéricos que enfatizam o maltrato e o uso da força para com os passageiros por parte dos revoltosos ${ }^{26}$ :

Os passageiros ficaram naturalmente aborrecidos com as notícias de mais demoras [...] Pacientemente, pois não queríamos recorrer a qualquer espécie de intimidação, tentámos explicar-lhes a situação e ajudá-los a adaptarem-se. [...] Uma pequena desordem entre eles, durante a qual gritaram que queriam abandonar o navio imediatamente - antes do desembarque dos passageiros - foi dispersa sem uso de força (GALVÃO, 1973, p. 253).

Na linha do depoimento de Galvão, segue o de Francisco Rico (apud MONTANYÀ, 2004, p. 157), exaltando o empenho de Pepe Velo que, com a sua retórica, faça os passageiros "serenarem os ânimos". Ao relato da revolta dos passageiros encontra-se vinculado um outro, o do protesto dos tripu- 
lantes que exigiam o desembarque imediato. São dois episódios diferentes nas narrativas acima, mas que aparecem figurados num só momento nos relatos de Sotomaior e o de Miguel Urbano.

O primeiro afirma ter sido o movimento capitaneado por "passageiros galegos da terceira classe" que foram reprimidos violentamente, sendo os "revoltosos" golpeados com as "coronhas das armas"27. Já Rodrigues (2001, p. 214) afirma o emprego das armas para conter "a gentalha irada", ou seja, uma parte da tripulação acompanhada por "dezenas de pessoas". Apesar destas afirmações feitas em suas memórias, o jornalista alega noutro texto, datado de 1972, que teria sido Pepe Velo a enfrentar a "multitud enfurecida", dominando-a "com palavras", deixando os tripulantes "avergonzados" e "las mujeres llorando" (TAVARES apud MONTANYÁ, 2004, p. 157), o que implica termos dois tipos de "memória" pertencentes a um só memorialista.

Para além desses relatos, a ideia de um "protesto" isento de cenas de violência por parte dos revoltosos está presente em muitas das reportagens ditas "imparciais", como a publicada na revista norte-americana Life, no dia 10 de Fevereiro de 1961, na qual as cenas narradas misturam actos de revolta e de desespero por parte de um grupo de passageiros diante do racionamento de alimentos e água imposto frente ao não abastecimento regular do paquete (PASSANGERS WERE EITHER..., 1961, p. 33).

O final do episódio é marcado pela decisão de entregar o paquete às autoridades brasileiras, ante a confirmação do apoio do presidente Jânio Quadros. Com honras oficiais, o Santa Maria é confiado ao comando da Marinha brasileira e os revoltosos recebidos em terra como exilados políticos. Entretanto, o que poderia parecer uma operação de revolta fracassada, como afirmam alguns periódicos, acaba por transformar-se no maior acto de propaganda contra os regimes ditatoriais ibéricos, atingindo nomeadamente Salazar.

SANTA MARIA: um ACTO de PROPAGANDA MOdERna CONTRA OS REGIMES DITATORIAIS IBÉRICOS

If it was conceived as a rebellion, it was a flop. But if it was a publicity stunt, it was imbued with idealism and conducted with a flamboyance that forced the world's attention on an issue that the world had long ignored (PORTUGAL: REVOLT..., 1961).

GEARING also played host to 66 correspondents and photographers from all corners of the world. They were warned that only the most austere conditions would be encountered board the GEARING due to our lack of extra bunks, but these hardy individuals had come a long way to get close to the SANTA MARIA and they were not to be denied. The correspondents included re- 
presentatives from NBC, ABC, LIFE, N.Y. TIMES, AP, UPI, CBS, LONDON

DAILY NEWS, PARIS MATCH and many others (AT SEA ..., 1961).

O impacto mediático do episódio do Santa Maria abriu um espaço único para a oposição, nos meios de comunicação de todo o mundo, malgrado as tentativas da imprensa pró-salazarista e dos órgãos de comunicação do regime em diminuir ou oferecer uma visão "não política" do acontecimento, reduzindo a tomada do paquete a um acto de pirataria.

Na verdade, o episódio gera uma verdadeira corrida ao local de fundeamento do Santa Maria na esperança de obter a exclusividade da cobertura jornalística. Por razões políticas, como é o caso do jornalista português exilado, Miguel Urbano Rodrigues, ou simplesmente, por razões profissionais, ocorre uma verdadeira "caça" ao paquete em mar aberto. Argumentações e contradições à parte, os depoimentos revelam o impacto mediático que cerca o episódio:

Era final de Janeiro, pleno verão em Recife, quando os repórteres chegaram [...] Lúcio e Miguel eram apenas mais dois deles, que chegaram no dia 29, para participar da corrida em busca do luxuoso transatlântico Santa Maria. [...] (Lúcio) foi conversando com os pescadores no porto, no fim de tarde, pagando cachaça, que foi assuntando sobre o navio. Desafiava-os, dizendo que nenhum deles seria capaz de encontrar o navio, que deveria estar debaixo do nariz deles. Finalmente, um deles topou, ele sabia onde o navio estava. Só faltava agora Lúcio "convencê-lo". Era o mestre Óscar Arthur.[...] quando o mestre chegou, já de madrugada, tinha mudado de idéia. Não queria mais levá-lo. Calmamente, Lúcio, que sempre andava "maquinado", teve uma conversa final - de pescador mineiro para pescador pernambucano. "Você tem duas opções, ou nos leva até lá, ou nos leva até lá!!!”. Na época este fato foi omitido, mas revelado para amigos e familiares. Como quem tem juízo sempre obedece - e o calibre impressionava -, o pescador levou os dois repórteres até o Santa Maria ${ }^{28}$.

Iniciei uma luta contra o tempo. Fui até ao porto e procurei saber onde poderia alugar um barco pequeno [...] Localizar o homem foi uma façanha. Acabamos por descobri-lo num bordel [...] Estava embriagado. Alugar alugava, mas, para dizer a verdade, somente sabia navegar à vista da costa. De latitudes e rádios não entendia patavina. Era contrabandista e no negócio fazia a rota da Guiana Francesa...

Tive uma ideia Tirei do bolso um mapa da Varig, que trouxera do avião, e comecei a ler os nomes que assinalava entre os paralelos nomeados por Galvão, inquirindo se reconhecia esses lugares a 30 milhas de distância. Ao 
citar o farol do Cabo Tamandaré, resmungou 'esse sim, conheço de muito longe!' [...] Entretanto desencadeara-se a tempestade, e a rádio informou que o porto fechara e nenhuma embarcação podia sair sem autorização. Outro contratempo: quando o barco se preparava para deixar o molhe, apareceu um grupo de jornalistas [...] tive de exibir um revólver (do António Lúcio) quando o norte-americano pretendeu entrar (RODRIGUES, 2001. p. 204-5).

O acto mais "inovador" em termos jornalísticos é levado a cabo por Gil Delamare, representante da Agência Delmas, responsável pela cobertura fotográfica da revista Paris Match. O jornalista francês vai ao encalço do Santa Maria a bordo de um avião, pulando de pára-quedas para as águas circundantes ao paquete, sendo então recolhido pela tripulação ${ }^{29}$. O resultado é uma reportagem de capa na revista sobre "La fantastique aventure de Galvão et des pirates de la revolution” (PARIS MATCH, 1961).

$\mathrm{Na}$ verdade, o posicionamento internacional da imprensa perante o episódio pode ser dividido em apoios ou "condenações", segundo a linha ideológica das publicações. É o caso dos "Diários Associados", de Assis Chateaubriand, no Brasil, elemento próximo ao salazarismo e que "proíbe" aos seus jornalistas qualquer menção favorável aos revoltosos nos jornais da sua rede ${ }^{30}$ :

Aí nós estamos em 1960, 1961, foi quando aconteceu o primeiro sequestro político da história moderna. [...] O Calazans que era um superchefe de reportagem, não existem mais como ele, tinha trabalhado no Recife. Pegou o telefone, ligou para o Recife [...] arranjou um repórter no Recife, colocou-o em um barco e mandou ele ir, porque o Santa Maria ficou fundeado a talvez umas 100 milhas da costa, não era longe, em uma hora ou duas chegava-se lá $[. .$.$] ele chegou ao Santa Maria e fotografou. Voltou, mandou o filme por$ um passageiro de um vôo - era assim que se fazia -, o filme chegou e nós pá! demos na página central do tablóide. A página central do tablóide era o local onde podíamos abrir bem as fotos, na capa e na página central. E saiu a manchete 'Repórter do Diário de Notícias junto ao Santa Maria. Entrevista com o comandante, o Capitão Galvão'. Fantástico! Aí vem o recado do Chateaubriand 'nem mais uma linha, nem mais uma linha a respeito, nada, nem contra nem à favor.'.

Em alguns periódicos, ocorre também uma "mudança" de argumento à medida que o acto passa a ser encarado como a expressão de uma luta 
política e não somente um "acto de pirataria", como desejam os regimes ibé$\operatorname{ricos}^{32}$. Na revista Life, temos um exemplo deste tipo de linguagem ambígua através de dois artigos; um realizado com base nas declarações dos feridos desembarcados na Ilha de Santa Lucia, no seu número de 3 de Fevereiro de 1961; o outro é o próprio editorial da revista. No primeiro caso, como seria de esperar, os relatos realizados por Carlos de Carvalho, um dos enfermeiros do paquete, falam do clima de "horror" passado no paquete aquando da sua tomada pelos revoltosos (CREW MEMBER'S ACCOUNT..., 1961, p. 30-1). No entanto, o editorial prefere discutir a legitimidade do acto, acompanhando a própria postura do governo americano:

But Jefferson's Great additionnal principe of political liberty is not yeat a universal part of this consensus. Perhaps the greatest lesson of the Santa Maria is that this world sense of law, valuable as it is and efective as it on the sea, will not run far enough until law everywhere includes Jefferson's principes. Dictator Salazar would scarrely need tor fear for Portugal's chips on the eas if His political opponents had free expression at home (ADVENTURE AT SEA..., 1961, p. 34).

No Brasil, o posicionamento dos periódicos do grupo de Chateaubriand e de jornais como $O$ Globo é posto em xeque por jornais, como a Tribuna da Imprensa, que assumem uma postura favorável aos oposicionistas ibéricos ${ }^{33}$. A mesma dicotomia aparece nos principais jornais da colónia portuguesa, nomeadamente dois deles, a Voz de Portugal, de cunho salazarista, e o Portugal Democrático, órgão da oposição exilada naquele país. O primeiro, publicado no Rio de Janeiro, reafirma, no seu noticiário, os títulos dos jornais publicados em Lisboa, "denunciando": "traição, sangue e morte no assalto ao Santa Maria" (VOZ DE PORTUGAL, 1961, p. 1-7). O segundo menciona o episódio com reservas, tendo em conta que também segue a linha de um outro periódico publicado clandestinamente em Portugal, o Avante, órgão do Partido Comunista Português ${ }^{34}$.

A aventura do Santa Maria apaixonou o mundo. Mas, independentemente de outras considerações, serviu para que o mundo tomasse consciência, mais uma vez, da existência de uma ditadura nefasta, desavergonhada e assassina, que é uma nódoa na civilização contemporânea [...] O episódio do Santa Maria foi, simbolicamente, a guerra civil que não queremos, para derrubar Salazar e a sua camarinha. Mas pôs o mundo perante um dever inadiável de honra e de decência: o isolamento desse bando oligárquico 
cujos tentáculos se entendem pelo mundo inteiro [...] (PORTUGAL EM LIBERDADE, 1961, p. 1).

Assim sendo, condenado pelo regime, olhado com reservas pelos opositores comunistas ou saldado como acto revolucionário o episódio do Santa Maria ganha as páginas do jornal, causando um impacto maior do que o esperado pelos próprios protagonistas. A aliança de diversos factores explicita o porquê do espaço que lhe é dedicado nos periódicos e nos noticiários internacionais. Do ponto de vista político, o "Santa Maria”é favorecido pelo clima criado com a chegada de John Kennedy à Casa Branca e expectativas internacionais em torno da Guerra Fria, para além de toda a movimentação em torno do reconhecimento internacional dos movimentos independentistas e o próprio cenário de democratização "à esquerda" apontado por Jânio Quadros quando da sua vitória eleitoral no Brasil. Por outro lado, o avanço da foto-reportagem ${ }^{35}$, a popularização das grandes revistas e das reportagens sensacionalistas, do noticiário televisivo e da possibilidade da transmissão directa via rádio ${ }^{36}$ incita toda uma dinâmica de impacto mediático que transforma o evento do paquete "Santa Liberdade" num verdadeiro "espectáculo", no qual entrevistas, fotografias e imagens directas contribuem directa ou indirectamente para a propaganda da oposição antisalazarista emigrada em todo o mundo.

O Governo Brasileiro e o Santa Maria: do posicionamento de Jânio Quadros aos MECANISMOS DE VIGILÂNCIA DO ESTADO

Com referência à notícia publicada no Diário de São Paulo de ontem, dia 29, com os dizeres "Galvão é meu amigo, não entregarei o Santa Maria a ninguém", apuramos em conversa com o Dr. Adib Dmetri o Dauar, médico residente na Vila Maria [...] teria o nosso Presidente Eleito afirmado, em tom de blaque, vai ver que tão logo eu assuma a Presidência da República o Henrique Galvão vai atracar o paquete em porto brasileiro. ${ }^{37}$

Para alguns autores, a ida do Santa Maria para o Brasil já estaria determinada muito antes dos acontecimentos que forçaram uma mudança nos planos originais dos revoltosos: a ida para Fernando Pó, onde os espanhóis estabeleceriam a sua base, seguindo os portugueses para Angola ${ }^{38}$. Na verdade, o encontro do comando do DRIL com o então candidato à presidência do Brasil, Jânio Quadros, quando da sua visita a Caracas, em Abril de 1960 (ANTUNES, 1991) ${ }^{39}$, teria determinado a decisão de seguir com o paquete para um bordo brasileiro. Escudado na afirmação de Jânio de apoio aos 
revoltosos e na sua posse como presidente em Fevereiro de 1961, Henrique Galvão teria optado por transformar a "Operação Dulcineia" numa grande demonstração de força contra o regime.

No entanto, a concessão de asilo político por parte de Jânio Quadros ao grupo do Santa Maria gera a desconfiança de sectores mais conservadores da sociedade brasileira, acostumada a traçar um quadro de boas relações com o governo de Lisboa e com a colónia portuguesa pró-salazarista no Brasil. O clima de Guerra Fria aliado ao crescente anti-comunismo que, em 1964, desemboca no golpe e na ditadura militar leva o Departamento de Ordem Política e Social, nomeadamente o seu núcleo estadual em São Paulo, o Departamento Estadual de Ordem Política e Social Paulista, a empreender uma cerrada vigilância sobre os oposicionistas antisalazaristas radicados na capital de São Paulo, já que é nesta cidade a concentração maior do núcleo de exilados e emigrados políticos do regime de Salazar ${ }^{40}$. Tal processo de "vigilância", ainda que englobe todas as actividades realizadas pelos exilados e emigrados políticos portugueses naquele país, desde o final dos anos cinquenta, ganha força após a chegada dos revoltosos do Santa Maria, crescendo à medida que se aproxima o golpe militar. Em quase todos eles podemos notar a indicação de envio para o Consulado Português, o que comprova a colaboração entre os dois órgãos, malgrado a posição oficial da presidência da República brasileira.

Desta forma, os integrantes do agora denominado "Santa Liberdade" são logo identificados à saída do Porto de Recife, tendo acesso ao "Modelo 19 ”, ou seja, o documento de identidade necessário para a permanência de estrangeiros no país. Após isto, seguem para o Rio de Janeiro, passando, grande parte do grupo, para a região de Campinas, onde passam a habitar uma casa rural e são vigiados constantemente pelo DEOPS ${ }^{41}$.

Em detrimento da pouco vigilância exercida sobre os membros do comando espanhol, Pepe Velo e Sotomaior, Henrique Galvão é seguido de perto pelas autoridades que lhe dedicam longos relatórios relatando os seus contactos com os restantes dos exilados radicados em São Paulo, nomeadamente a sua participação em reuniões públicas, como a promovida pelo Centro Republicano Português de São Paulo, em 5 de Março de 1961, onde a sua permanência é assinalada com ênfase, apesar de permanecer no recinto apenas alguns minutos ${ }^{42}$. Ironicamente, a tónica no "perigo comunista" que perpassa em todos os relatórios e ofícios é o pretexto fundamental para a vigilância do anti-comunista Galvão. Somente na segunda metade da década de sessenta, após a "Operação Vago" e a sua posterior "retirada" do cenário da "acção directa”, é que o seu nome desaparece dos relatórios oficiais do DEOPS ${ }^{43}$.

Heloisa Paulo. 1961: o assalto do Santa maria e o desmoronar do regime salazarista em Portugal 


\section{Santa Maria: o conflito pela memória}

La oposición puede justificarse tanto desde el plano de la ética política puesto que ningún grupo o fracción posee el derecho de arrogarse el privilegio de poseer la verdad política - (¿existe la verdad política?) - ni, por ende, acaparar el Poder, como desde el plano de la utilidad política, puesto que la oposición contribuye a un gobierno más eficaz de la sociedad. [...] La memoria individual está estructurada por los grupos a los que pertenecen los indiviuos - la família, la clase, la religión, la nación - y se apoya eny está conformada por la memoria social, que se representa y transmite a través de prácticas culturales simbólicas o mnemotécnicas que dan forma y sustentan las identidades colectivas. A medida que las identidades de grupo se ajustan a las alteraciones que se preciben en el médio social y político, la memoria social también se recontruye (BADIA, 1970, p. 35).

O relato de um episódio pode conter uma série de informações que ultrapassam a aparente simplicidade da sua descrição. A importância da chamada "pequena história" já há muito foi "recuperada" pelos Annales, recolocando o facto na sua verdadeira dimensão ${ }^{44}$. Não se trata de contestar a veracidade e a importância do factual, mas questionar a estrutura da memória e do relembrar dos acontecimentos e a sua importância na construção de uma "memória oficial" e, a partir daí, a própria produção historiográfica existente. No caso da história das oposições em Portugal, em relação ao episódio do Santa Maria, é indagar as razões do tipo de enfoque dos memorialistas e a dicotomia que coloca o episódio "enclausurado" entre a constatação da sua importância em termos do seu impacto interno no regime e a sua "pouca importância” na historiografia sobre a trajectória das oposições. Por fim, é tomar o episódio e o seu relato como um exercício para a investigação da história contemporânea, cujos actores são uma espécie "nova" de documentação, capazes de apresentarem contradições acerca de um mesmo tema, ou ainda, responderem directamente ao historiador, oferecendo sempre uma outra possibilidade de análise a partir dos argumentos que utilizam.

Em primeiro lugar, cumpre salientar quais são os tipos de memórias publicadas e, a partir daí, tentar estabelecer os parâmetros que as norteiam. O livro de Galvão deve ser considerado como uma obra de "propaganda", escrita no "calor da hora", cujo objectivo é demonstrar a legitimidade do acto e afastar dos leitores qualquer imagem que possa induzir na confirmação dos noticiários favoráveis ao salazarismo, dentro e fora de Portugal. Favorecido pela projecção que detém então nos noticiários, o autor exacerba o seu 
protagonismo, relegando para o segundo plano os companheiros espanhóis. De igual forma, descarta da narrativa a presença de alguns personagens, como Miguel Urbano Rodrigues com quem rompe logo após a sua chegada ao Brasil. No seu relato não há conflitos internos e mesmo o episódio do ataque inicial e a morte do tripulante é tratada com vénia, já que este caiu "nobremente no cumprimento do seu dever" (GALVÃO, 1973. p. 174).

Os relatos posteriores são apresentados com uma elaboração diferente, cuja distância temporal do acontecimento e a influência dos factos posteriores influenciam o "rememorar", exacerbando as contradições então existentes. A narrativa de Sotomaior é marcadamente " romanceada", apesar do autor só admitir o recurso ao que chama "diálogo cénico" e com base nas notas tomadas aquando da entrevista com os representantes das autoridades navais norte-americanas (SOUTOMAIOR, 2010,. p. 218). Os diálogos são descritos ao pormenor, mesmo passados 11 anos do ocorrido ${ }^{45}$, incentivando uma certa ideia de fidelidade no leitor. Apesar disto, no relato é perceptível a influência das distensões posteriores entre os dois grupos, sobretudo entre os objectivos do DRIL, na sua vertente espanhola, e o lado português, representado por Galvão e que abandona o projecto de acção conjunta. Para Sotomaior o importante é ressaltar o papel dos espanhóis, apagado na época pelo protagonismo de Galvão nos meios de comunicação. Ao mesmo tempo, tenta justificar o que considera o "fracasso" dos planos originalmente propostos pelo DRIL, ou seja, a posse do navio e o seu encaminhamento para o território africano, atribuindo aos portugueses a culpa na entrega de relatórios falseados, para além dos atrasos na operação que inviabilizaram a ida até Fernando do Pó. Por fim, ao refazer os seus últimos tempos no Brasil, descreve, com tintas negras, o clima de perseguição das autoridades do Rio de Janeiro ${ }^{46}$ e assinala o rompimento entre Delgado e Galvão como um símbolo da cisão na oposição portuguesa, fruto do conflito pessoal dos dois militares.

Na verdade, enquanto escreve, Sotomaior vivencia o reavivar do movimento oposicionista antifranquista, apesar das divisões internas que não são características dos opositores portugueses. No entanto, o PCE, ressurgido em 1964, solicita a unidade da oposição e apela para a acção directa, enquanto coordena uma série de movimentos grevistas, unindo sindicalistas e membros do partido. A partir de 23 de Janeiro de 1971, estas manifestações ganham uma maior violência, graças à actuação do seu "grupo de combate", a FRAP, Frente Revolucionário Antifascista e Patriota ${ }^{47}$. Paralelamente, o ETA, braço armado do Partido Nacionalista Basco, eleva o número dos atentados cometidos contra membros e instituições franquistas iniciados na década de

Heloisa Paulo. 1961: o assalto do Santa maria e o desmoronar do regime salazarista em Portugal 
sessenta. Assim sendo, a tentativa de justificar o fracasso de um movimento que poderia "ter destruído a ditadura de Salazar" e permitido "lutar com certas vantagens contra a ditadura franquista" (SOTOMAIOR, 2010, p. 330), surge num momento bem agitado na história das oposições espanholas na qual é preciso "fazer contas" com o passado da oposição.

Em contrapartida, Miguel Urbano Rodrigues não "justifica” o fracasso e sim "confirma" a tese de que qualquer actuação armada isolada não poderia trazer benefícios para a luta oposicionista, seguindo a orientação partidária do PCP, para o qual retorna após o período de afastamento e que abrange a sua actuação no Santa Maria. A sua participação no episódio é considerada como "filha do romantismo revolucionário, ou para ser mais preciso, de um infantilismo revolucionário" (RODRIGUES, 2001, p.218). A sua argumentação é a mesma de inúmeros outros memorialistas que, uma vez integrados no PC, relegam as acções condenadas pelo partido ${ }^{48}$.

Desta forma, enquanto fonte documental, as memórias são muito semelhantes ao material fílmico, já que as imagens construídas são sempre influenciadas e marcadas pelas impressões adquiridas entre o acto e o recordar ${ }^{49}$. Como no género do filme "histórico", a história "rememorada" ganha contornos actuais e sofre o peso da leitura institucional, imposta pela historiografia, pelo partido ou instituições. Recordar é como o montar do cenário de uma película, onde os personagens impostos pelo guião podem sofrer cortes e ter as suas posições em cena alteradas, segundo o olhar do realizador.

Assim sendo, os memorialistas apresentam ângulos de visão que lhe são impostos pelo posicionamento que guardavam na altura dos eventos, pelos laços ideológicos e políticos mantidos ou estabelecidos posteriormente e pela própria capacidade física imposta ao rememorar, onde os acontecimentos mais distantes ganham força de acordo com o impacto que possuem na trajectória de vida de quem relembra. Um exemplo bem interessante é a descrição do dia do embarque feita por Galvão e por Camilo Mortágua, este último "iniciante" quando do assalto ao Santa Maria:

Foi numa sexta feira do mês de Janeiro de 1960, dia 20. Henrique Galvão no seu livro sobre o assalto ao Santa Maria, na página 159, diz que - 'o dia amanheceu claro e brilhante com um sol glorioso' - cá por mim, nada vos posso dizer sobre o assunto.

Não me lembro de ter olhado para o céu, nem prestado atenção ao tempo que fazia...

As minhas preocupações eram outras. Manhã cedo as rádios estavam a 
anunciar que por causa dos distúrbios e manifestações, tinha sido decretado o recolher obrigatório. Íamos ter problemas! (MORTÁGUA, 2009. p. 221).

Em conclusão, como já vimos o estudo do episódio do Santa Maria pode fornecer dados interessantes para a análise do movimento oposicionista nas décadas de sessenta e setenta. Por um lado, pode explicitar a importância do regime de Salazar no contexto internacional no início da década de 1960, realçando as relações mantidas com os Estados Unidos, ou mais precisamente com o Brasil num período imediatamente anterior ao golpe militar. Num outro ângulo, pode servir de "exemplo" para as mudanças ocorridas na forma de veiculação dos eventos através das novas abordagens do noticiário. No entanto, é através das estratégias de discurso usadas para explicar a participação de membros de cada um dos sectores da oposição no evento que podemos entender as distensões internas da oposição anti-salazarista, transformando as memórias em depoimentos indirectos que ultrapassam o espaço e o tempo tratados nas narrativas.

1961: the Seizure of the Santa Maria and the collapse of Salazar's regime in PORTUGAL

ABSTRACT: In January 1961, an episode marks the history of the opposition to Salazar's regime in Portugal: the seizure of the ship Santa Maria, a luxury vessel and one of the prides of Salazar's regime. There are quite a few books dealing with this Santa Maria episode, in Portuguese, Spanish, Galician and Catalan. Nevertheless, the vast majority is made up by testimonials of participants. Our objective is the analysis of those testimonials, bringing a new angle to the interpretation of the fact. Keywords: Opposition, Salazar, Memory, Relations Brazil-Portugal.

NOTAS

1 Sobre o tema ver, entre outros, Marques (1975), Campinos (1975), Farinha (1998) e Raby (1980).

2 Sobre o tema, ver Paulo (2009).

3 Criado em 1933, com o objetivo de defender a autonomia da Galícia, Países Bascos e Catalunha, tal movimento é revivido pelos exilados nacionalistas, visando formar uma frente de combate contra o franquismo. Sobre o tema ver, entre outros, Rivas (1999) e Estevez (1991).

4 Afonso Castelao foi o fundador do Partido Galeguista, defensor do nacionalismo galego.

Heloisa Paulo. 1961: o assalto do Santa maria e o desmoronar do regime salazarista em Portugal 
5 Sobre os problemas do reconhecimento da República espanhola no exílio, ver, entre outros, Sobre os problemas do reconhecimento da República espanhola no exílio, ver, entre outros, Lleonart e Anselm (1978).

6 Sobre o tema, ver Sanchez-Albornoz (1999).

7 Rubem Braga (1957, p. 5) afirma taxativamente num artigo: "O facto é este: Portugal vive sob uma ditadura que reprime da maneira mais severa qualquer oposição".

8 Em maio, são presos pela Polícia Política e Social, no Rio de Janeiro, dois portugueses suspeitos de estarem a tramar um atentado contra Craveiro Lopes: Manuel Lourenço Neto, ex-oficial da Marinha, que já havia sido julgado pelo Tribunal Militar da Marinha e condenado a dezoito meses de prisão e à perda dos direitos políticos pela realização de uma campanha comunista no interior das Forças Armadas, e José da Costa Bastos, também acusado de crime idêntico, mas que fora absolvido pelo mesmo tribunal. Sobre o tema, ver Paulo (2009, p. $355 \mathrm{ss})$.

9 São interessantes os verbetes sobre o episódio, contidos em alguns dicionários de História Contemporânea, como Andrade (2002, p.269-70), Melo (1996, p. 67-9) e Raby (2000, p. 396-7).

10 Sobre o tema, ver, entre outros, Raby (1988) e Sanchez-Albornoz (1999).

11 Sobre o tema, ver, entre outros, Piñeiro (2008).

12 Os trabalhos sobre Humberto Delgado são inúmeros, tendo em conta a sua posição de "herói nacional", construída pela oposição após o seu assassinato em 1965. Alguns dos trabalhos biográficos, no entanto, pecam pela total falta de rigor histórico, como a biografia escrita pelo seu neto, Rosa (2008). Quanto a Henrique Galvão, os trabalhos biográficos são escassos, entre eles, ver Montoito (2005).

13 Sobre o tema, ver, entre outros, Diogo (2000).

14 Sobre o governo de Jânio Quadros e a sua política internacional, ver, entre outros, Benevides (1982).

15 Em português, entre outros, ver Antão e Tavares (2008), em espanhol, ver, entre outros, Garcia (2005) e Bayón (1999) e, em catalão, Montanyà (2004).

16 A Operação inicialmente leva o nome de "Operación Compostela", mas é rebaptizada por Henrique Galvão diante da escolha do paquete português. Sobre o tema, ver Piñeiro (2008, p. 36).

17 Sotomaior narra a "falsificação" de um relatório que teria sido entregue por Camilo Mortágua a Henrique Galvão. Este documento, para além de apontar um forte armamento no interior do paquete português, narra as difíceis condições 
impostas em Miami quando da passagem do Santa Maria por aquele porto. Tal relato teria sido decisivo na decisão da escolha do navio e da sua captura antes de este tomar o rumo dos USA (SOUTOMAIOR, 2010, p. 45, 46). Tal facto é negado por Camilo Mortágua (entrevista com a autora, dia 08 de Outubro de 2010).

18 São diversos os motivos da cisão entre os dois opositores, nomeadamente as questões relativas ao comando do movimento e, de forma mais crucial, o apoio dado pelo sector delgadista ao movimento de libertação das colónias.

19 Ambos os jornais são editados em São Paulo. Sobre o tema ver, entre outros, Paulo (2000) e Silva (2006).

20 Não inserimos aqui o relato de Camilo Mortágua pelo facto de estar restrito ao período da tomada do paquete Santa Maria, não oferecendo uma visão dos acontecimentos posteriores à noite de 22 de Janeiro. No entanto, pudemos contar com o seu depoimento pessoal no qual não atribui a si próprio responsabilidades decisórias no comando na Operação Dulcineia, apesar de assumir-se como "lugar direito" de Galvão.

21 No assalto são feridos dois oficiais, sendo morto um outro, João José Nascimento Costa, o único elemento que ofereceu resistência ao assalto.

22 Camilo Mortágua confirma o posicionamento contrário de Galvão ao desembarque, o que comprova parcialmente o depoimento de Sotomaior e vai de encontro com toda a formação militar de Henrique Galvão.

23 Declaração de Camilo Mortágua à autora (08 de Outubro de 2010).

24 Sobre o tema, nomeadamente o posicionamento de Portugal frente aos Estados Unidos no período, ver, entre outros, Telo ( 1996) e Rodrigues (2010).

25 Documentação do National Archives and Records Administration. Washington, EUA (apud MONTANYÀ, 2004, p. 153).

26 Por exemplo, o jornal La Vanguardia, publicado em Barcelona, no dia 4 de Fevereiro de 1961, na página 10, apresenta uma reportagem com passageiros do Santa Maria intitulada: Hambre, Sed, Calor y Vejaciones durante las Jornadas Dramáticas del Santa Maria. Sobre o impacto do episódio em Espanha ver, entre outros, Garcia (2005).

$27 \mathrm{O}$ autor chega a afirmar que só não disparou contra os revoltosos porque estes seriam galegos, como o próprio Sotomaior, e que teria sido felicitado pelo Capitão de Mar e Guerra da Marinha Brasileira, Aristides Leite (SOUTOMAIOR, 2010, p. 252-4).

28 Cf. no site: <http://www.memorialpernambuco.com.br/memorial/117historia/ santamaria.htm $>(2010)$.

Heloisa Paulo. 1961: o assalto do Santa maria e o desmoronar do regime salazarista em Portugal 
29 Sobre o tema, ver Sousa (2000).

30 Assis Chateaubriand é descrito como um "salazarista declarado" (MORAIS, 1994, p. 612).

31 Entrevista de Alberto Dines, repórter do jornal Diário da Noite (cf. no site: $<$ http://www.tvebrasil.com.br/observatorio/sobre_dines/memoria.htm>, 2010), por ocasião do sequestro do Santa Maria. Ele foi despedido do jornal, pois o mesmo pertencia aos chamados Diários Associados. Sobre o tema ver, entre outros, Carneiro (1999).

$32 \mathrm{Na}$ imprensa portuguesa, ainda mais que na espanhola, o ato é considerado um caso de pirataria articulado com as primeiras incursões da União das Populações Africanas contra o regime. Ver, por exemplo, o noticiário da primeira página do Diário da Manhã e do Diário de Notícias, ambos de 07 de fevereiro de 1961.

33 O jornal pertencia ao político Carlos Lacerda, então governador do Rio de Janeiro e apoiante dos antisalazaristas desde que demonstrassem o seu "anticomunismo". Ver as citações na obra de Galvão (1973).

34 No seu número 297, da $1^{\text {a }}$ quinzena de Fevereiro de 1961, em Novas Derrotas do Salazarismo, afirma-se o posicionamento do PCP contrário à luta armada: "Apesar das consequências positivas da operação do Santa Maria e da nossa inteira solidariedade aos patriotas que nela participaram, o PC sente-se no dever de alertar o povo português contra as ilusões que tais formas de luta poderão semear entre o democratas portugueses" (VOZ DE PORTUGAL, 1961, p. 2).

35 Sobre o tema ver, entre outros, Burke e Briggs (2004).

36 O episódio é coberto por todas as estações de rádio do Brasil, para além da cobertura televisiva, ver entre outros Oficio datado de 29 de Janeiro de 1961 do DEOPS, onde são enumerados programas de rádio e apresentada cópia da entrevista de Humberto Delgado para a televisão (Arquivo do DEOPS. 50E-29-13).

37 Relatório Reservado n. 45, datado de 30 de Janeiro de 1961, endereçado ao Delegado Titular do Departamento de Ordem Politica e Social do Estado de São Paulo (Arquivo do DEOPS, 50 E- 29-15).

38 Ver, entre outros, Piñero (2008. p. 35) e Montanyà (2004, p. 102ss).

39 Sobre o tema, ver ainda Fiuza (2007).

40 Sobre o tema, ver Paulo (2000).

41 Ver, entre outros, Ofício do DEOPS datado de 19 de Fevereiro de 1961, onde são listados os que estão no sítio e as actividades que desenvolvem, revelando a vigilância constante por parte das autoridades paulistas (ARQUIVO DO DEOPS, 50E-29-19).

42 Ver Relatório n. ${ }^{\circ}$ 110-61, Reunião do Centro Republicano Português do dia 5 
de Março de 1961 (ARQUIVO DO DEOPS, 50E-29-23).

43 A chamada "Operação Vago" reúne Camilo Mortágua, o braço direito de Galvão no Santa Maria, e outros opositores, entre eles, Carlos Palma Inácio, ex-aviador, e Amândio Silva. Em 10 de Novembro de 1961, numa acção até então inédita e cujo mentor é Galvão, o grupo sequestra um avião da TAP que fazia a ligação entre Lisboa e Casablanca e durante algum tempo sobrevoa a capital portuguesa atirando panfletos contrários ao regime de Salazar.

44 Ver, entre outros, Burke (1991, p. 58ss).

45 O original do livro data de 1972.

46 É interessante a descrição que faz de Carlos Lacerda, então governador do Estado da Guanabara, naquele momento, um elemento próximo ao sector democrático da Oposição exilada. Tal posicionamento só se modifica quando, neste mesmo ano de 1961, ele declara o seu apoio ao regime na luta pela manutenção das colónias. Ver, entre outros, reportagens do jornal Portugal Livre (1961).

47 Ver, entre outros, Tusell, Alted e Mateos (2009). Sobre a Flap, está disponível na internet um site próprio (<http://www.frap.es $>$ ).

48 Sobre o tema, ver Paulo (2010).

49 Sobre a temática ver, entre outros, Fentress e Wickham (1994) e Halbwachs (1990).

\section{REFERÊNCIAS}

ADVENTURE AT SEA: a parable. Life, 03 fev. 1961, p. 34.

ANDRADE, J. Operação Dulcineia. In: ANDRADE, J. Dicionário do 25 de Abril. Verde Fauna, Rubra Flora. Lisboa: Nova Arrancada, 2002. p. 269-270.

ANTÃO, N. M.; TAVARES, C. G. Henrique Galvão e o assalto ao Santa Maria. Percurso de uma dissidência do Estado Novo e suas repercussões internacionais. Sapiens - Revista de História, Património e Arqueologia, n. 0, dez. 2008. Disponível em: <http://www.revistasapiens.org/Biblioteca/numero0/henriquegalvao.pdf $>$. Acesso em: 2010.

ANTUNES, Jo. F. Os americanos e Portugal (1961). Kennedy e Salazar: o leão e a raposa. Lisboa: Difusão Cultural, 1991.

ARQUIVO DO DEOPS, 50E-29-19.

ARQUIVO DO DEOPS. 50E-29-13.

AT SEA: 11 February 1961. U.S.S. GEARING (DD-710) c/o Fleet Post Office New York. New York. Disponível em : <http://solantamity.com/Media/Documents/ Familygram5.htm>. Acesso em: 2010. 
BADIA, J. F. En torno a una Teoría de la Oposición en el sistema democratico-liberal. Revista de Estúdios Políticos, n. 173, 1970.

BAYÓN, M. Santa Liberdade. Barcelona: Planeta, 1999.

BENEVIDES, M. V. O governo Jânio Quadros. São Paulo: Brasiliense, 1982.

BOYD, C. De la memoria social a la memoria histórica. In: JULIÁ, S. (Dir.). Memoria de la Guerra y del franquismo. Madrid: Santilanna, 2006.

BRAGA, R. Portugueses. Diário de Notícias, Rio de Janeiro, 04 de maio de 1957, p. 5. BURKE, P. A Escola dos Annales 1929-1989. A Revolução Francesa da Historiografia. São Paulo: edunesp, 1991.

BURKE, P.; BRIGGS, A. Uma história social da mídia. Rio de Janeiro: J. Zahar, 2004. CAMPINOS, J. A ditadura militar: 1926-1933. Lisboa: D. Quixote, 1975.

CARNEIRO, G. Brasil, primeiro: história dos Diários Associados. Brasília: Fund. Assis Chateaubriand, 1999.

CORTESÃO, J. Saudação ao povo espanhol. Libertação, Ano I, n. 1, Rio de Janeiro, 14 abr. 1947, p. 1.

CREW MEMBER'S ACCOUNT Od Night of alarm, murder, hijackind and terror. Life, 03 feb. 1961, p. 30-31.

DIÁRIO DA MANHÃ, 07 fev. 1961.

DIÁRIO DE NOTÍCIAS, 07 fev. 1961.

DIOGO, L. C.; JANUÁRIO, R. Direito internacional do mar. Coimbra: Almedina, 2000.

ESTEVEZ, X. De la Tríplice Aliança al Pacto de San Sebastian (1923-1930). San Sebastian: Cuadernos Universitários, 1991.

FARINHA, L. O reviralho. Revoltas republicanas contra a ditadura e o Estado Novo. 1926-1940. Lisboa: Estampa, 1998.

FENTRESS, J.; WICKHAM, C. Memória social. Novas perspectivas sobre o passado. Lisboa: Teorema, 1994

FIUZA, A. F. As relações entre as ditaduras do Brasil e de Portugal e a vigilância política sobre os exilados durante as décadas de 1950 e 1960. In: I COLÓQUIO DE HISTÓRIA DA UNIVERSIDADE FEDERAL RURAL DE PERNAMBUCO - Brasil e Portugal: nossa história ontem e hoje, 3-5 out. 2007. Anais..., 2007.

GALVÃO, H. O assalto ao Santa Maria. Lisboa: Delfos, 1973.

GARCIA, A. R. El secuestro del Santa Maria en la prensa del regímen franquista. Revista Historia y Comunicación Social, Madrid, n. 10, 2005.

HALBWACHS, M. A memória colectiva. São Paulo: Vértice, 1990.

HAMBRE, SED, CALOR y vejaciones durante las jornadas dramáticas del Santa Hist.R., Goiânia, v. 16, n. 1, p. 53-80, jan./jun. 2011 
Maria. La Vanguardia, 04 fev. 1961, p. 10. Disponível em: <http://www.hemeroteca. lavanguardia.es>. Acesso em: 2010.

HERBERG, M. La Guerra de España y la resistência española. Madrid: Amargord, 2009.

LLEONART Y ANSELM, A. J.; CASTIELA Y MAIZ, F. M. Espana y ONU, (19451946). Madrid: CSIC, 1978. V. I.

MARQUES, A. H. de O. (Org). O general Sousa Dias e as revoltas contra a ditadura, 1926-1931. Lisboa: D. Quixote, 1975.

MELO, D. de. Assalto ao Santa Maria. In: ROSAS, F.; BRITO, J. M. B. (Coords.). Dicionário de História do Estado Novo. Venda Nova: Bertrand, 1996. p. 67-69. V. I.

MONTANYÀ, Xavier. Pirates de la llibertat. Barcelona: Empúries, 2004.

MONTOITO, E. Henrique Galvão ou a dissidencia de um cadete do 28 de Maio (1927-1952). Lisboa : Centro de História da Universidade de Lisboa, 2005.

MORAIS, F. Chatô o rei do Brasil, a vida de Assis Chateaubriand. São Paulo. Cia. das Letras, 1994.

MORTÁGUA, C. Entrevista, 08 de outubro de 2010.

MORTÁGUA, C. Andanças para a liberdade. Lisboa: Esfera do Caos, 2009.

PARIS MATCH, 04 fev. 1961.

PASSANGERS WERE EITHER NEAR tears wills anxiety or near revolt because of inadequate food and water. Life, 10 feb. 1961, p. 33.

PAUlO, H. Aqui também é Portugal?. A colónia portuguesa do Brasil e o salazarismo, Coimbra: Quarteto, 2000.

PAULO, H. O exílio português no Brasil: Os 'Budas' e a oposição antisalazarista. Portuguese Migrations in Comparison: Historical Patterns and Transnational Communities. Portuguese Studies Review, Peterborough, Ontario, v. 14, n. 2, jun. 2009.

PAULO, H. História e memórias: oitenta anos do 3 Fevereiro de 1927. In : PAULO, H. (Coord.). Memórias das oposições (1927-1969). Coimbra: Minerva, 2010.

PIÑEIRO, A. Xosé Velo Mosquera, poeta e soñador, político e pensador, revolucionario e mestre. Vigo: Ir Indo, 2008.

PORTUGAL EM LIBERDADE. Portugal Democrático, São Paulo, fev. 1961, p. 1.

PORTUGAL: REVOLT ON THE HIGH SEAS, FRIDAY. Times, 03 feb. 1961.

Disponível em : <http://www.time.com/time/magazine/article/0,9171,872033,00. html\#ixzz12ReGsWWH>. Acesso em: 2010.

RABY, D. L. A resistência antifascista em Portugal. Lisboa: Salamandra, 1980.

RABY, D. L. A resistência antifascista em Portugal. 1941-1974. Lisboa: Salamandra, 1988.

Heloisa Paulo. 1961: o assalto do Santa maria e o desmoronar do Regime SAlazarista EM Portugal 
RELATÓRIO N. 110-61, Reunião do Centro Republicano Português do dia 5 de Março de 1961. Arquivo do DEOPS, 50E-29-23.

RELATÓRIO RESERVADO N. 45, datado de 30 de Janeiro de 1961, endereçado ao Delegado Titular do Departamento de Ordem Politica e Social do Estado de São Paulo, Arquivo do DEOPS, 50 E- 29-15.

RIVAS, X. L. B. El Nacionalismo como estratégia: fundamentos historicos y alcance político de la declaracion de Barcelona. RIPS, v. 1, n.1, p. 99-112, 1999.

RODRIGUES, L. N. Orgulhosamente sós? Portugal e os Estados Unidos no início da década de 1960. Disponível em: <http://www.ipri.pt/investigadores/artigo. php?idi=8\&ida=140\#_ftn11>. Acesso em: 2010.

RODRIGUES, M. U. O tempo e o espaço em que vivi. I. Procurando um caminho. Porto: Campo das Letras, 2001.

ROSA, F. D. Humberto Delgado, biografia do General Sem Medo. Lisboa: A Esfera dos Livros, 2008.

SANCHEZ-ALBORNOZ, S. C. La Oposición democrática a las dictaduras ibéricas (1940-1945). Cuadernos de Historia Contemporanea, Madrid, Universidad Complutense, n. 21, 1999.

SILVA, D. M. A oposição ao Estado Novo no exílio brasileiro 1956-1974. Lisboa: ICS, 2006.

SITE: <http://www.memorialpernambuco.com.br/memorial/117historia/santamaria.htm>. Acesso em: 2010.

SITE: <http://www.tvebrasil.com.br/observatorio/sobre_dines/memoria.htm>. Acesso em: 2010.

SOUSA, J. P. Uma história crítica do fotojornalismo ocidental. Florianópolis: Grifos, 2000.

SOUTOMAIOR, Jorge. Eu roubei o Santa Maria. Lisboa: Labirinto das Letras, 2010. TELO, A. J. (Org.). Portugal e a Nato: o reencontro da tradição atlântica. Lisboa: Cosmos, 1996.

TUSELL, J.; ALTED, A.; MATEOS, A. (Coord.). La oposición al Régimen de Franco. Madrid: Ed. da Uned, 1991.

VOZ DE PORTUGAL, 29 jan. 1961, p. 1-7.

ZEIGER, H. A. The seizing of the Santa Maria. New York: Popular Library, 1961. 